\title{
STUDI MENGENAI PELANGGAN YANG MEMBELI DARI PERUSAHAAN MULTI-LEVEL MARKETING DI JAKARTA
}

\author{
William indrajaya \\ Program Studi Magister Manajemen Universitas Tarumanagara \\ William.in.ja@gmail.com
}

\begin{abstract}
Multi-level Marketing (MLM), also known as network marketing is a relatively grown industry with its size and reputation are growing rapidly. According to the Direct Selling Association (DSA), direct selling is a US\$ 183 billion industry worldwide with an annual growth rate at 2 percent. Multi-level Marketing was brought to Indonesia from the US over a decade ago and has been growing for almost a decade here in indonesia. It unique operating format seems to contravene all traditional sales principles. In Indonesia, the number of sales which was generated by people who involved in direct selling almost hit the 1.2 billion mark. According to WFDSA (2016), total distributor who have join the Multilevel Marketing business in indonesia is around 14 million. These member are people who join Multi-level Marketing company as their full time job and some of them as their part-time job. This study surveys 200 customers in Indonesia area concerning their motivation of buying from MLM company, their demographic characteristic and teir attitudes as consumers towards MLM products. In addition we also compare the consumer satisfaction of MLM products to that of the similar products on traditional market. The result shown that the major factor of purchasing MLM Product is because pressure from friend or relatives and the product special function. I also found that skin care and supplements is the most initial buying and rebuying categories in the MLM Industries. Major faction that influence customer satisfaction on MLM Products is product quality, refundable, after sales services, corporation reputation, brand reputation, delivery speed, and payment variety.
\end{abstract}

\section{Keywords : Customer satisfaction, Multi-level Marketing, Traditional Marketing.}

\section{PENDAHULUAN}

Cara penjualan secara multi-level marketing adalah salah satu cara untuk menjual dari perusahaan langsung kepada pengguna (end-user) dan sudah berumur lebih dari ratusan tahun(Vander Nat \& keep,2002). Marketing sendiri adalah proses mempertemukan antara kebutuhan dan penawaran (Kotler \& Keller,2012). Proses penjualan secara multi-level marketing sendiri di Indonesia dimulai dari tahun 2001(Kementrian Perdagangan, NOMOR : 289/MPP/Kep/10/2001). Dapat dilihat dalam angka pertumbuhan penjualan mlm secara global di Indonesia mengalami penurunan dan peningkatan yang berarti (2014: 1.122 Juta USD, 2015: 1.069 Juta USD, 2016: 1.183 Juta USD).

\section{LANDASAN TEORI}

Single level marketing Menurut Grayson and Berry single-level marketing organization adalah sebuah proses marketing yang mengatur managemen perusahaan dan supervisor penjualan. Beberapa perusahaan biasanya memiliki satu atau dua level kepemimpinan seperti.

country manager dan regional manager. Multi Menurut Vander Nat dan Keep (2002) multilevel marketing adalah sebuah perwujudan dari penjualan langsung, dimana perserta bekerja sebagai agen yang bekerja secara lepas yang juga berarti mereka tidak secara langsung terlibat dalam struktur organisasi sebuah perusahaan namun tetap menjalankan peran mereka. Segmentasi marketing bias terbagi menjadi beberapa segmentasi seperti segmen pasar 
konsumen (geografis, demografi, psikologis, dan prilaku), segmen bisnis (demografis, variable operasional, pendekatan pembelian, factor situasi, karakter personal). Targeting adalah proses untuk menentukan target mengunakan 5 pendekatan measureable, substantial, accesible, differentable, dan actionable. Positioning adalah cara sebuah merek memposisikan dan mengasosiasikan dirinya kepada pelanggan. (Kotler \& Keller, 2012).

Pada penelitian ini mengunakan 200 orang dengan kisaran umur yang sama dengan yang sebelumnya pernah dilakukan di Taiwan. Metode pengujian yang akan digunakan adalah independent samples $t$ test. Artinya masing-masing sample akan diuji satu kali saja mengenai tingkat kepuasan yang mereka alami ketika berbelanja produk MLM maupun produk Tradisional Marketing.

\begin{tabular}{|l|c|c|}
\hline \multicolumn{1}{|c|}{ FAKTOR } & JUMLAH CUSTOMER & PERSENTASE \\
\hline TEKANAN KERABAT & 100 & 50 \\
\hline FUNGSI KHUSUS & 90 & 45 \\
\hline MENCARI UANG & 67 & 33.5 \\
\hline MEREK TENAR & 65 & 32.5 \\
\hline KUALITAS PRODUK & 35 & 17.5 \\
\hline AFTER SALES BAIK & 25 & 12.5 \\
\hline TANPA SEBAB & 25 & 12.5 \\
\hline MURAH & 20 & 10 \\
\hline FASHIONABLE & 5 & 2.5 \\
\hline
\end{tabular}

Tabel 1 FAKTOR UTAMA PEMBELIAN PRODUK MLM

Dari hasil penelitian yang dilakukan didapatkan bahwa factor utama pembelian produk MLM adalah karena tekanan teman atau kerabat dan fungsi khusus produk. Hasil ini menunjukkan bahwa terjadi kesalahan fokus promosi untuk metode Multi-level Marketing.

\begin{tabular}{|c|c|c|}
\hline SUMBER INFORMASI & MEAN & STD. DEV \\
\hline TEMAN / KENALAN & 4.50 & 0.501 \\
\hline MEDIA ONLINE & 3.40 & 1.079 \\
\hline DIRECT MARKETING & 2.05 & 0.834 \\
\hline RADIO & 2.04 & 0.825 \\
\hline SALESMAN & 2.03 & 0.820 \\
\hline MEDIA CETAK & 1.98 & 0.832 \\
\hline
\end{tabular}

Tabel 2 SUMBER INFORMASI PRODUK MLM

Menurut Kolter \& Keller (2012), konsumen bisa mendapatkan informasi dari beberapa sumber yaitu sumber personal (teman dan kenalan), sumber iklan (iklan online dan selebaran, tenaga penjual, dealer, bentuk kemasan, barang contoh di toko), sektor publik (media cetak, lembaga survei, youtube), pengalaman pribadi (memegang, memeriksa dan mengunakan produk). Sumber-sumber informasi ini memiliki mempengaruhi calon pembeli dengan cara ynag berbeda-beda yang mengerucut pada keputusan pembelian.

Pada tabel 2 bahwa dua faktor yang paling dipercaya untuk mendapatkan informasi mengenai produk MLM adalah teman dan media online. Mengapa teman menjadi ranking pertama? Menurut Farooq \& Jan (2012), teman adalah salah seorang yang paling dipercaya, dan testimoni pengalaman dari seseorang yang teman yang dipercaya akan membuat orang yang mendengar lebih percaya karena sumber informasi yang didapatkan apa adanya. Media online menduduki tingkat kedua karena kemudahan untuk mengakses internet. 


\begin{tabular}{|c|c|c|c|}
\hline RANK & PRODUCT & INITIAL PURCHASE & REPURCHASING \\
\hline 1 & SKIN CARE & $71 \%$ & $71 \%$ \\
\hline 2 & SUPLEMENTS & $50 \%$ & $45 \%$ \\
\hline 3 & PERSONAL CLEANING & $10 \%$ & $6 \%$ \\
\hline 4 & WATER / AIR FILTER & $11 \%$ & $9 \%$ \\
\hline 5 & HEALTHY EQUIPMENT & $12 \%$ & $3 \%$ \\
\hline
\end{tabular}

Tabel 3 KATEGORI PRODUK MLM yang akan dibeli dan akan dibeli lagi

Tabel 3 menunjukan bahwa kategori produk yang paling sering dibeli pertama kali untuk di coba adalah skincare produk perawatan kulit (71\%), suplement (50\%), personal cleaning (10\%), Water / Air filter (11\%), Healty Equipment (12\%). Yang menjadi alasan mengapa produk perawatan kulit dan suplement adalah karena kedua produk ini habis ketika dikonsumsi sehingga kebutuhan untuk membeli kembali pada kategori ini cukup besar yaitu skincare $(71 \%)$ dan suplement (45\%) sedangkan untuk produk non konsumtif seperti water / air filter dan alat kesehatan memiliki tingkat pembelian produk awal yang lebih rendah.

Proses pengambilan keputusan adalah sebuah proses yang complex dan tidak mudah mulai dari identifikasi masalah, pencarian informasi, evaluasi alternative yang ada, keputusan pembelian dan prilaku setelah pembelian. Proses mencari evaluasi setiap alternatif yang ada tentu saja mempertimbangkan banyak faktor antara lain faktor kultural, faktor personal, faktor sosial dan faktor pisikologis, faktor usia, faktor tingkat pendidikan, faktor jenis kelamin dan status perkawinannya karena orang yang sudah menikah biasanya memiliki cara pengambilang keputusan yang berbeda dengan yang belum menikah. Faktor yang mempengaruhi keputusan pembelian produk MLM di Jakarta adalah sebagai berikut :

\begin{tabular}{|c|c|c|c|}
\hline RANK & FAKTOR & MEAN & STD. DEV \\
\hline 1 & KUALITAS PRODUK $(\mathrm{X} 1)$ & 4.870 & 0.337 \\
\hline 2 & PRICE FAIRNESS $(\mathrm{X} 2)$ & 4.515 & 0.501 \\
\hline 3 & MONEY BACK GUARANTEE $(\mathrm{X3})$ & 4.215 & 0.412 \\
\hline 4 & AFTER SALES $(\mathrm{X} 4)$ & 4.065 & 0.809 \\
\hline 5 & PAYMENT MECHANISM $(\mathrm{X} 11)$ & 3.475 & 1.252 \\
\hline 6 & DIFFERENTIATION $(\mathrm{X} 10)$ & 3.365 & 1.229 \\
\hline 7 & KEMASAN PRODUK $(\mathrm{X} 12)$ & 3.345 & 1.214 \\
\hline 8 & SALES PERSON $(\mathrm{X} 8)$ & 3.295 & 1.231 \\
\hline 9 & BRAND REPUTATION $(\mathrm{X} 7)$ & 3.215 & 1.330 \\
\hline 10 & CORP REPUTATION $(\mathrm{X} 5)$ & 3.185 & 1.252 \\
\hline 11 & PHYSICAL EVIDENCE $(\mathrm{X} 6)$ & 3.185 & 1.349 \\
\hline 12 & DELIVERY SPEED $(\mathrm{X} 9)$ & 3.155 & 1.300 \\
\hline
\end{tabular}

Tabel 4 faktor yang mendorong pembelian produk-produk MLM

Menurut tabel 4 terdapat ranking faktor-faktor mana saja yang mempengaruhi keputusan pembelian produk MLM dari paling berpengaruh sampai dengan yang kurang berpengaruh. Empat faktor yang paling berpengaruh adalah kualitas produk, price fairness, moneyback guarantee dan after sales service. Setelah mengetahui data ini, marketer harus mengunakan strategi pendekatan yang mengakomodasi ke-empat faktor ini. 
Independent Samples Test

\begin{tabular}{|c|c|c|c|c|c|c|c|c|c|c|}
\hline & & \multicolumn{2}{|c|}{ Equality of Variances } & \multicolumn{7}{|c|}{ t-test for Equality of Means } \\
\hline & & \multirow[b]{2}{*}{$\mathrm{F}$} & \multirow[b]{2}{*}{ Sig. } & \multirow[b]{2}{*}{$t$} & \multirow[b]{2}{*}{$\mathrm{df}$} & \multirow{2}{*}{$\begin{array}{l}\text { Sig. (2- } \\
\text { tailed) }\end{array}$} & \multirow{2}{*}{$\begin{array}{c}\text { Mean } \\
\text { Difference }\end{array}$} & \multirow{2}{*}{\begin{tabular}{|c|} 
Std. Error \\
Difference
\end{tabular}} & \multicolumn{2}{|c|}{ Interval of the } \\
\hline & & & & & & & & & Lower & Upper \\
\hline \multirow[t]{2}{*}{$\begin{array}{l}\text { PRODUCT } \\
\text { QUALITY (X1) }\end{array}$} & $\begin{array}{l}\text { Equal variances } \\
\text { assumed }\end{array}$ & 9.333 & .002 & 7.745 & 398 & .000 & .630 & .081 & .470 & .790 \\
\hline & $\begin{array}{l}\text { Equal variances not } \\
\text { assumed }\end{array}$ & & & 7.745 & 394.343 & .000 & .630 & .081 & .470 & .790 \\
\hline \multirow{2}{*}{$\begin{array}{l}\text { PRICE } \\
\text { FAIRNESS } \\
(X 2)\end{array}$} & $\begin{array}{l}\text { Equal variances } \\
\text { assumed }\end{array}$ & 1.910 & .168 & -1.710 & 398 & .088 & -.155 & .091 & -.333 & .023 \\
\hline & $\begin{array}{l}\text { Equal variances not } \\
\text { assumed }\end{array}$ & & & -1.710 & 395.637 & .088 & -.155 & .091 & -.333 & .023 \\
\hline \multirow{2}{*}{$\begin{array}{l}\text { MONEY BACK } \\
\text { GUARANTEE } \\
(\mathrm{X} 3)\end{array}$} & $\begin{array}{l}\text { Equal variances } \\
\text { assumed }\end{array}$ & .733 & .392 & 12.584 & 398 & .000 & 1.040 & .083 & .878 & 1.202 \\
\hline & $\begin{array}{l}\text { Equal variances not } \\
\text { assumed }\end{array}$ & & & 12.584 & 397.656 & .000 & 1.040 & .083 & .878 & 1.202 \\
\hline \multirow[t]{2}{*}{$\begin{array}{l}\text { AFTER SALES } \\
(\mathrm{X} 4)\end{array}$} & $\begin{array}{l}\text { Equal variances } \\
\text { assumed }\end{array}$ & 36.943 & .000 & 8.628 & 398 & .000 & .585 & .068 & .452 & .718 \\
\hline & $\begin{array}{l}\text { Equal variances not } \\
\text { assumed }\end{array}$ & & & 8.628 & 329.993 & .000 & .585 & .068 & .452 & .718 \\
\hline \multirow{2}{*}{$\begin{array}{l}\text { CORP } \\
\text { REPUTATION } \\
(X 5)\end{array}$} & $\begin{array}{l}\text { Equal variances } \\
\text { assumed }\end{array}$ & 21.753 & .000 & 3.303 & 398 & .001 & .325 & .098 & .132 & .518 \\
\hline & $\begin{array}{l}\text { Equal variances not } \\
\text { assumed }\end{array}$ & & & 3.303 & 382.192 & .001 & .325 & .098 & .132 & .518 \\
\hline \multirow{2}{*}{$\begin{array}{l}\text { PHYSICAL } \\
\text { EVIDENCE } \\
(X 6)\end{array}$} & $\begin{array}{l}\text { Equal variances } \\
\text { assumed }\end{array}$ & .820 & .366 & -1.692 & 398 & .091 & -.155 & .092 & -.335 & .025 \\
\hline & $\begin{array}{l}\text { Equal variances not } \\
\text { assumed }\end{array}$ & & & -1.692 & 396.422 & .091 & -.155 & .092 & -.335 & .025 \\
\hline \multirow{2}{*}{$\begin{array}{l}\text { BRAND } \\
\text { REPUTATION } \\
(X 7)\end{array}$} & $\begin{array}{l}\text { Equal variances } \\
\text { assumed }\end{array}$ & 12.365 & .000 & -3.109 & 398 & .002 & -.280 & .090 & -.457 & -.103 \\
\hline & $\begin{array}{l}\text { Equal variances not } \\
\text { assumed }\end{array}$ & & & -3.109 & 383.557 & .002 & -.280 & .090 & -.457 & -.103 \\
\hline \multirow[t]{2}{*}{$\begin{array}{l}\text { SALES } \\
\text { PERSON }(X 8)\end{array}$} & $\begin{array}{l}\text { Equal variances } \\
\text { assumed }\end{array}$ & 9.583 & .002 & -.923 & 398 & .357 & -.085 & .092 & -.266 & .096 \\
\hline & $\begin{array}{l}\text { Equal variances not } \\
\text { assumed }\end{array}$ & & & -.923 & 387.310 & .357 & -.085 & .092 & -.266 & .096 \\
\hline \multirow[t]{2}{*}{$\begin{array}{l}\text { DELIVERY } \\
\text { SPEED (X9) }\end{array}$} & $\begin{array}{l}\text { Equal variances } \\
\text { assumed }\end{array}$ & .077 & .781 & -3.275 & 398 & .001 & -.305 & .093 & -.488 & -.122 \\
\hline & $\begin{array}{l}\text { Equal variances not } \\
\text { assumed }\end{array}$ & & & -3.275 & 396.019 & .001 & -.305 & .093 & -.488 & -.122 \\
\hline \multirow[t]{2}{*}{$\begin{array}{l}\text { DIFFERENTIA } \\
\text { TION }(X 10)\end{array}$} & $\begin{array}{l}\text { Equal variances } \\
\text { assumed }\end{array}$ & 3.513 & .062 & -3.937 & 398 & .000 & -.355 & .090 & -.532 & -.178 \\
\hline & $\begin{array}{l}\text { Equal variances not } \\
\text { assumed }\end{array}$ & & & -3.937 & 390.644 & .000 & -.355 & .090 & -.532 & -.178 \\
\hline \multirow{2}{*}{$\begin{array}{l}\text { PAYMENT } \\
\text { MECHANISM } \\
(\mathrm{X} 11)\end{array}$} & $\begin{array}{l}\text { Equal variances } \\
\text { assumed }\end{array}$ & 1.887 & .170 & -2.200 & 398 & .028 & -.205 & .093 & -.388 & -.022 \\
\hline & $\begin{array}{l}\text { Equal variances not } \\
\text { assumed }\end{array}$ & & & -2.200 & 389.993 & .028 & -.205 & .093 & -.388 & -.022 \\
\hline \multirow{2}{*}{$\begin{array}{l}\text { AESTHETIC } \\
\text { QUALITY } \\
(X 12)\end{array}$} & $\begin{array}{l}\text { Equal variances } \\
\text { assumed }\end{array}$ & 1.799 & .181 & -1.787 & 398 & .075 & -.170 & .095 & -.357 & .017 \\
\hline & $\begin{array}{l}\text { Equal variances not } \\
\text { assumed }\end{array}$ & & & -1.787 & 394.548 & .075 & -.170 & .095 & -.357 & .017 \\
\hline
\end{tabular}

Tabel 5 Tabel Independent Sample test yang mempengaruhi tingkat kepuasan produk MLM dan Tradisional marketing

Ada Perbedaan tingkat kepuasan antara konsumen yang membeli dari MLM dan toko fisik berdasarkan faktor kualitas produk, jaminan uang kembali, layanan purna jual, reputasi perusahaan, reputasi merek, kecepatan pengiriman barang, diferensiasi produk dan metode pembayaran yang digunakan tidak harus tunai. Tidak ada perbedaan tingkat kepuasan konsumen yang membeli dari MLM dan toko fisik berdasarkan faktor harga, bukti fisik, salesman dan bentuk kemasan produk. 


\section{Kesimpulan}

1. Faktor utama pendorong pembelian produk MLM di Jakarta karena tekanan kerabat dan fungsi khusus dari produk yang dijual.

2. Kategori produk yang paling sesuai di Jakarta adalah produk perawatan wajah dan supplement kesehatan.

3. Tingkat kepuasan yang menguntungkan sistem MLM menurut faktor kualitas produk, jaminan uang kembali, layanan purna jual dan reputasi perusahaan sedangkan pada took fisik menurut faktor diferensiasi produk, kecepatan pengiriman, reputasi merek, kemasan produk, harga yang masuk akal, salesman, kemudahan pembayaran dan bukti fisik

\section{Saran}

1. Distributor harus lebih tenang dan sabar dalam mempromosikan produk MLM agar tidak terbentuk citra bahwa faktor yang mendorong pembelian produk MLM adalah karena faktor tekanan dari teman atau kerabat bukan karena fungsi khusus produk. Jika bisa dilakukan maka pertumbuhan per tahun bisnis MLM akan kembali ke angka yang lebi besar daripada hanya sebesar $2 \%$ dibandingkan dengan tahun sebelumnya.

2. Faktor yang perlu segera ditingkatkan antara lain kemudahan untuk membayar, differensiasi produk, kemasan produk.

\section{DAFTAR PUSTAKA}

Albaum, Gerald and A. Peterson, Robert (2011). Multilevel (network) marketing. The Marketing Review, Vol 11 no 4.

Amir Heimana, Bruce McWilliams , Jinhua Zhao and David Zilbermand (2002). Valuation and management of money-back guarantee options. Journal of Retailing 78, pp 193205

Brigham, Eugene F., and Houston, Joel F. (2013). Fundamentals of Financial Management $\left(13^{\text {th }}\right.$ ed.), South-Western Cengage Learning : USA.

Colin, Gilligan and R. M. S. Wilson (2010). Strategic Marketing Planning. Routledge. New York, USA

David and Fred R. (2011). Strategic Management, Manajemen Strategis Konsep. Jakarta : Salemba Empat

Deepali Bhattacharjee (2016). Consumer in Direct selling-A case study of Assam. IOSR Journal Of Humanities And Social Science (IOSR-JHSS).Volume 21, Issue11, Ver. 10 (Nov. 2016) PP 01-09

Dessler \& Gary. (2013). Human Resources Management (13 ${ }^{\text {th }}$ ed.), Pearson International : USA

Diller, H. (2000), "Preiszufriedenheit bei Dienstleistungen. Konzeptionalisierung und explorative empirische Befunde", Die Betriebswirtschaft, Vol. 60 No. 5, pp. 570-87.

Farah Diba Abrantes Braga, Giuliana Isabella and José Afonso Mazzon (2013). Do Digital Wallets as a Payment Method Influence Consumer in Their Buying Behavior? EnAnpad http://www.anpad.org.br

Faraz Farooq and Zohaib Jan. (2012). The Impact of Social Networking to Influence Marketing through Product Reviews (2012). International Journal of Information and Communication Technology Research Volume 2 No. 8, August 2012

Galbraith, Jay R., (1977). Organization Design. Reading Massachusetts: Addison Wesley Publishing Company.

Garvin, D.A. (1987). Competing on the eight dimensions of quality. Harvard Business Review (HBR), Vol. 65, Issue 6, pp. 101-109.

Gaspersz, Vincent. (2012). Strategic Management, Bogor : Vinchristo Publ. 
Gregor, Bogdan and Wadlewski, A.A. (2013). "MULTI LEVEL MARKETING AS A BUSINESS MODEL". Marketing of Scientific and Research Organizations March 2013

Hitt, Michael, Ireland, R. Duane, E.Hoskisson, Robert, 2011. Strategic Management Competitiveness and Globalization. South-Western Cengage Learning : USA.

John Burnett, (2010), Introducing Marketing, Jacobs Foundation, Zurich, Switzerland

Kotler, Phillip and Keller, Kevin Lane. (2012). Marketing Management (14 ${ }^{\text {th }}$ ed.), Pearson International : USA

Kumar, S. Anil and Suresh, N. (2009). Operations Management, New Age International (P) Limited, Publishers : New Delhi

Kurt Matzler, Andreas Würtele and Birgit Renzl (2006) Dimensions of price satisfaction: a study in the retail banking industry. International Journal of Bank Marketing Vol. 24 No. 4, 2006 pp. 216-231

Porter,f Michael E. (2007). Strategi Bersaing (Competitive Strategy), Teknik Menganalisa Industri dan Pesaing. Karisma Publishing Group.

Pour B.S., Nazari K. and Emani M. (2013) The Effect of Marketing Mix in attracting Customers: Case study of Sederat Bank in Kermanshah Province, African Journal of Business Management, 7(34), pp.3272-3276

Rentz, J. C., Shepherd, D., Armen, Tashchian, A., Dabholkar, P. A. and Ladd, R. T. (2002). A measure of selling skill: Scale development and validation. The Journal of Personal Selling \& Sales Management, 22 (Winter), 13-21.

Riikka Kaipia .(2007). The effects of delivery speed on supply chain planning. Helsinki University of Technology, Espoo, Finland.

Rust, R.T. and Oliver, R.L. (1994). "Service quality: insights and managerial implications from the frontier", in Rust, R.T. and Oliver, R.L. (Eds),Service Quality: New Directions in theory and Practice, Sage Publications, Thousand Oaks, CA, pp. 1-19

Salah M. Diab (2014). Using the Competitive Dimensions to Achieve Competitive Advantage A Study on Jordanian Private Hospitals. International Journal of Academic Research in Business and Social Sciences, Vol. 4, No 9 (September), pp 138-150.

Sohi Ravipreet S. (1996). The effect of environmental dynamism and heterogeneity on salesperson's role perceptions, performance and job satisfaction. European Journal of Marketing, 30 (7), 49-67.

Vander Nat, P. J., \& Keep, W. W. (2002). Marketing fraud: An approach for differentiating multilevel marketing from pyramid schemes. Journal of Public Policy \& Marketing, 21(1), 139-151.

Walsh, G. \& Beatty, S. E. (2007). Customer-based corporate reputation of a service firm: Scale development and validation. Journal of the Academy of Marketing Science, 35, 127-143. doi:10.1007/s11747-007-0015-7

Wotruba, Thomas R. and Pribova, Marie .(1996). Direct Selling in an emerging market economy: a comparison of Czech/Slovak and US market characteristics and buying experiences. In The International Review of Retail, Distribution and Consumer Research, Vol. 6, No. 4 (October), pp 415-435.

Yuval Emek, Ron Karidi, Moshe Tennenholtz, and Aviv Zohar. (2011) Mechanisms for Multi-Level Marketing, ACM 978-1-4503-0261-6/11/06

http://www.kentgrayson.com/Grayson\%20Archive/directsellingchp.pdf (20 November 2017) https://repositorio.iscte-iul.pt/bitstream/10071/1162/1/Paper_347_IADIS2003.pdf

(25 November 2017)

http://www.cadsm.org/dsrc-cn/research/English/English\%20Papers/009.pdf (5 Juni 2017)

https://www.dsa.org/docs/default-source/ethics/legitimatecompanies.pdf?sfvrsn=2

(25 Desember 2017) 
https://infinitemlmsoftware.com/matrix-plan.php (20 Desember 2017) 
